\title{
PROPERTY EVALUATION OF HEMP - BAGASSE FIBER COMPOSITE - A REVIEW
}

\author{
Paras Tholiya \\ Department of General Engineering \\ Institute of Chemical Technology, Mumbai, \\ Maharashtra, India-400019
}

\begin{abstract}
Automobile industries move towards manufacturing using sustainable material development techniques to enhance fuel efficiency by increasing the parts strength with lightweight material. Natural fiber composite materials are one of the recent developing materials used to apply for construction, electronics, automobile sectors etc. In the present unsustainable environment condition, the natural fiber composites serve as a better material in terms of biodegradability, costeffectiveness, and has improved resistance. This experimental study aims to fabricate the treated HempBagasse fiber composite for automobile applications and evaluate properties like mechanical, thermal, and permeance. Fabrication of two different treated fibrous fillers with the polymeric matrix can be done using the hand lay-up method. To study the fillers enhancement and behavior with the resin, the different volume fraction of fibers is incorporated in resin. The overall property was done by as per ASTM standards, then the composition is optimized for future automobile applications like car door panels.
\end{abstract}

Keywords - Hemp Fiber, Bagasse Fiber, Natural Fiber Composite, Chemical Treatments, Composites

\section{INTRODUCTION}

The continuous improvement of environmental awareness, ecological issues, and new regulations, bio-fiber Reinforced plastic composite materials have received increasing attention in recent decades. Research and development of natural fiber as reinforcing material for automotive sectors are growing interest to scientists and engineers. These days, naturally occurring fibers is an interesting option in the composite technology; the drive is environmentally friendly, the renewability of these fibers, good sound abatement capability, and improved fuel efficiency due to reduced component weight [1]. Composite materials have achieved success in the application of semi-structural and structural.

A composite is made by combining two or more substances that mixed and have very different properties. The two substances join together to give unique properties [2]. The current challenge is to create the composite materials price

\author{
Dr. S.P. Deshmukh \\ Department of General Engineering \\ Institute of Chemical Technology, Mumbai, \\ Maharashtra, India- 400019
}

effectively. Thus, the use of natural fibers as the reinforcement in the composite material is the actual way to decrease the composite material cost and study its properties and the effect of different surface treatments on fibers [3].

\section{NATURAL Fiber COMPOSITE}

In the last decade, the natural fibers have been increasing the environmental alertness, which has increased the interest to users of the plant-based natural fibers instead of man-made synthetic fibers in polymer composite materials. Conducted extensive research on natural fibers such as hemp, jute, kenaf, sisal, banana, sugar-cane bagasse, pineapple, wood fiber, and straw. The results represent that the natural fibers have the large potential as an effective reinforcement in polymer matrices [4]. The plant or vegetables based natural cellulose fibers are obtained from various parts of the plants or vegetables. Although natural fibers have many ecological advantages over glass fibers, they also have many disadvantages, such as lower impact strength and higher moisture absorption, causing dimensional changes, leading to microcracks and poor thermal stability, which may also cause thermal degradation during processing. The composites moisture absorption containing natural fibers had many adverse effects on their properties and affected their long-term performance. Using a suitable surface treatment method, the resistance to moisture absorption, and the enhanced mechanical properties of natural fibers have been achieved [5]. The hemp fiber is obtained from the outer layer or the bast of the Cannabis plant. It's one of the quickest growing plant. Later the fibers remove from the stem and cut to shorter lengths [6]. Bagasse is the major by-product of the sugarcane industry. Bagasse is a fiber residue that remains in crushing the sugarcane stalks [7]. The properties of hemp fiber and bagasse fiber are shown in table 1 .

Table-1 Properties of hemp and bagasse fiber

\begin{tabular}{|c|c|c|c|c|}
\hline $\begin{array}{c}\text { Sr. } \\
\text { no. }\end{array}$ & Properties & $\begin{array}{c}\text { Hemp } \\
\text { Fiber }\end{array}$ & $\begin{array}{c}\text { Bagasse } \\
\text { fiber }\end{array}$ & Ref. \\
\hline 1 & Density $\left(\mathrm{g} / \mathrm{cm}^{3}\right)$ & 1.48 & 1.25 & {$[8]$} \\
\hline 2 & Moisture Content & 12 & 49 & {$[4][9]$} \\
\hline
\end{tabular}


International Journal of Engineering Applied Sciences and Technology, 2021

Vol. 6, Issue 1, ISSN No. 2455-2143, Pages 376-382

Published Online May 2021 in IJEAST (http://www.ijeast.com)

\begin{tabular}{|c|c|c|c|c|}
\hline & $(\%)$ & & \\
\hline 3 & $\begin{array}{c}\text { Tensile Strength } \\
(\mathrm{MPa})\end{array}$ & $\begin{array}{c}310- \\
750\end{array}$ & $20-290$ & {$[4][8]$} \\
\hline 4 & $\begin{array}{c}\text { Young's Modulus } \\
(\mathrm{GPa})\end{array}$ & $\begin{array}{c}30- \\
60\end{array}$ & 17 & {$[8]$} \\
\hline 5 & Failure Strain (\%) & $2-4$ & $1-1.5$ & {$[4]$} \\
\hline 6 & Elongation (\%) & 1.6 & $6.3-7.9$ & {$[8]$} \\
\hline
\end{tabular}

mate- rials and the chemical treatments done on the fibers to improve the bonding between the fiber and the matrix.

1. Impact of fiber content on the mechanical properties of composite:

- Akarsh S, Darshan H R et al. [10] studied the mechanical properties of hemp - bagasse fiberreinforced by epoxy hybrid composite for different ratios of fibers to $10 \%$ and $20 \%$ were prepared, by the tensile and flexural properties of hybrid composites are improved markedly as compared to un hybrid composite. These fibers were treated with a $5 \%$ concentration of $\mathrm{NaOH}$ and $\mathrm{NaCl}$ to remove the natural fibers lignin and cellulose content.

\section{Chemical TREATMENTS}

Understand surface adhesives and chemical composition Ingredients are important for the development of natural fiber-reinforced composite materials. The primary objective of surface treatment on natural fibres is to improve the bonding strength to enhance stress transferability between the fibre and the matrix in the composites. Cellulose, hemicellulose, and lignin in the natural fibres are the reason for its high moisture absorption and dimensional instability [8]. The hydrophilic hydroxyl groups in the reinforcement causes poor adhesion between the fibre and the hydrophobic polymer matrix. So, to enhance interfacial bonding effectiveness, fibre surface needs to be modified with different chemical treatments, reactive additives, and coupling agents. As a result, improves the properties of the composite. Chemical modifications are done to improve the interface of fibers. Chemical coupling agents are generally facilitating two-stage. The first stage is to react with hydroxyl groups of cellulose and the second stage is to react with the functional groups of matrixes [9]. The table 2 shows the chemical composition of hemp and bagasse fiber.

Table-2 Chemical composition of hemp and bagasse fiber[4]

\begin{tabular}{|c|c|c|}
\hline Fibre & Cellulose(wt $\%)$ & Hemicellulose(wt\%) \\
\hline Hemp & 68 & 15 \\
\hline Bagasse & 55.2 & 16.8 \\
\hline
\end{tabular}

\section{LITERATURE SURVEY}

Researchers have begun to attend to natural fiber composite materials (i.e hemp - bagasse fibers), which are made of natural or synthetic resins and reinforced with natural fibers. Natural fiber has many advantages, such as low density, low cost, lightweight, etc. Many researchers have found the mechanical properties of natural fiber polymer composite

\begin{tabular}{|c|c|c|c|c|c|c|c|}
\hline \multirow{2}{*}{$\begin{array}{c}\text { Sr. } \\
\text { no }\end{array}$} & $\begin{array}{c}\text { Specimen } \\
\text { composition }\end{array}$ & $\begin{array}{c}\text { Tensile Test } \\
\text { load } \\
{[\mathrm{N}]}\end{array}$ & $\begin{array}{c}\text { Ultimate } \\
\text { tensile } \\
\text { strength }\end{array}$ & $\begin{array}{c}\text { Peak } \\
\text { load } \\
{[\mathrm{N}]}\end{array}$ & $\begin{array}{c}\text { 3-point } \\
\text { flexural } \\
\text { strength }\end{array}$ & $\begin{array}{c}\text { Load } \\
\text { in } \\
\mathrm{kg}\end{array}$ & $\begin{array}{c}\text { Average } \\
\text { BHN }\end{array}$ \\
\hline 1 & $10 \%$ & 3150 & 42 & 134 & 71.67 & 60 & 83 \\
\hline 2 & $20 \%$ & 2170 & 28.93 & 146 & 77.90 & 60 & 71 \\
\hline
\end{tabular}

Table-3 Mechanical Test Results [8]

We obtained the tensile strength of the laminate is increased by $10 \%$ fiber proportion and flexural strength of laminate will increase in $20 \%$ fiber loading. Also, hardness tests were performed, on $10 \%$ fiber loading the strength of the hybrid composite increased shown in table 3. Mechanical properties of natural fiber reinforced hybrid composites are completely depending on the amount and type of fibers used. The specimen was prepared by as per ASTM standard and tested.

- Venkatesh.B, Sathyapal Reddy.L et al. [11] evaluate mechanical behavior study and develop a polymer matrix composite material for 4, 7, 10, 13 wt.\% of hemp fibers are mixed with a matrix material of epoxy resin by using hand lay-up method. It was observed from the result that the tensile strength increases with increasing fiber content, up to 10 wt. $\%$, and then decreases at 13 wt.\% respectively. The impact test also increases at $10 \mathrm{wt} . \%$ and the compression test, the increase in hemp fiber content of the material and the fibers of different layers are determined by using Scanning Electron Microscope. The fabricated composite samples were cut according to the ASTM standards and its characterization is performed. Figure 1 shows the SEM image of a fractured surface of a composite material under tensile load [12]. In Figure 1A shows that the fiber breaks and fibers pulled from the loading direction 


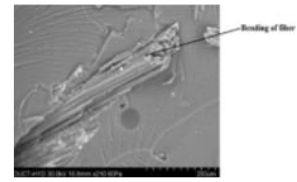

Figure 1A

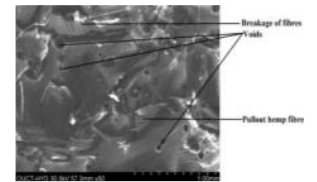

Figure1B

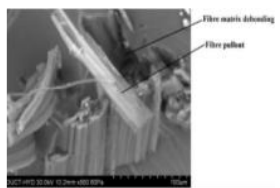

Figure 1C matrix is visible. Figure 1B shows due to poor resin compatibility with natural fibers, voids formed due to fiber pull-out were also visible and figure $1 \mathrm{C}$ shows the fiber pull out were de-bonding of fiber with the matrix is visible.

- R. Bhoopathi, M. Ramesh et al. [13] fabricated the composite by using banana-glass fiber, hemp-glass fiber and banana-hemp-glass fiber reinforced hybrid composites and the mechanical properties such as tensile strength, flexural strength and impact strength of these composites are evaluated. The laminate fabricated by hand lay-up process. The banana-glass fiber composites have more tensile strength than other composites and the maximum flexural strength hold by the banana-hemp-glass fiber-reinforced composite. The morphological analysis, observed the interface characteristics, the fracture surface, the fiber failure mode, fiber pull-out, and fiber dislocation. Researchers suggest that this banana-hemp-glass fiber reinforced hybrid epoxy composites are often used as an alternate material for synthetic fiberreinforced composite materials.

- N S Venkatesha Gupta, Akash et al. [14] studied the evaluation of mechanical properties of alkaline treated sisal/hemp fiber reinforced hybrid composite. In this study, a hybrid composite was produced by a different percentage of fiber loading that can be achieved by a compression molding method. Sodium hydroxide $(\mathrm{NaOH})$ treatments are removing the impurities and modify the surface properties. The 40 wt.\% of sisal/hemp fiber reinforced hybrid composite material exhibits higher tensile and flexural strength than other hybrid composite materials. It increases the hardness strength with the increasing the wt.\% of fiber content. The morphological observation was performed using a scanning electron microscope to analyze interface characteristics, internal structure, and fracture surface.

- Maneesh Tewari, V. K. Singh et al. [15] studied the bagasse glass fiber composite materials with $15 \mathrm{wt} \%$, $20 \mathrm{wt} \%, 25 \mathrm{wt} \%$, and $30 \mathrm{wt} \%$ bagasse fibers with $5 \mathrm{wt} \%$ glass fiber. Mixing of bagasse with glass fiber also increases the modulus of elasticity. (SEM) Scanning Electron Microscope shows that the fiber with a diameter of $13 \mu \mathrm{m}$ and a length of $61 \mu \mathrm{m}$ has good bonding to the resin matrix. The addition of bagasse fiber reduces the tensile strength, but glass fibers addition increases the final tensile strength. The addition of bagasse fiber also improves the impact strength because it is more elastic than the matrix material. The composite with glass and bagasse fiber has more bending strength than commercially available composite material. The addition of fiber increases the water absorption capacity. This test is important where composites are used in moisture affected areas.

\section{Effect of surface treatment:}

- Balamurali Krishna C M, Chandrashekar Babu KC et al. [9] studied the effect of water absorption hemp bagasse fiber reinforced with epoxy hybrid composite. A composite material is considered because it is light in weight, easy to use, low in thickness, and has a high mass-to-weight ratio and biodegradability. Treat the filaments with $5 \% \mathrm{NaOH}$ and $5 \% \mathrm{NaCl}$ solutions to remove lignin content and improve grip property. The fabricated composite samples were cut according to the ASTM standards and calculated the Weight percentage of both the samples $(20 \% \& 30 \%)$ in normal and distilled water by changing time. The weight percentage is increased in normal water and distilled water in 24 and 48 hours with a given volume fraction given in table 4 .

\begin{tabular}{|c|c|c|c|c|c|}
\hline $\begin{array}{c}\text { Types of } \\
\text { Immersion }\end{array}$ & \multicolumn{2}{|c|}{ Water Absorption in 24 hrs } & \multicolumn{2}{|c|}{$\begin{array}{c}\text { Water Absorption in } \\
48 \text { hrs }\end{array}$} \\
\hline & $\begin{array}{c}\text { Vol. } \\
\text { fraction } \\
\text { of } \\
\text { specimen }\end{array}$ & $\begin{array}{c}\text { Wt. of } \\
\text { specimen } \\
\text { before } \\
\text { (gm) }\end{array}$ & $\begin{array}{c}\text { Wt. of } \\
\text { specimen } \\
\text { after } \\
\text { (gm) }\end{array}$ & $\begin{array}{c}\text { Wt. of } \\
\text { specimen } \\
\text { before } \\
\text { (gm) }\end{array}$ & $\begin{array}{c}\text { Wt. of } \\
\text { specimen } \\
\text { after } \\
(\mathrm{gm})\end{array}$ \\
\hline $\begin{array}{c}\text { Normal } \\
\text { Water }\end{array}$ & $20 \%$ & 16.75 & 18.03 & 16.72 & 20.32 \\
\cline { 2 - 6 } & $30 \%$ & 17.05 & 18.37 & 17.15 & 20.36 \\
\hline $\begin{array}{c}\text { Distilled } \\
\text { Water }\end{array}$ & $20 \%$ & 16.65 & 18.21 & 16.24 & 19.89 \\
\cline { 2 - 6 } & $30 \%$ & 18.27 & 20.26 & 18.12 & 20.12 \\
\hline
\end{tabular}

Table-4 water Absorption Test

- For 24 hrs normal water, the weight percentage is increased and it is calculated by this formula [W\% (W(f) - W(i)/ W(f)], we get $6.99 \%$ for $20 \%$ volume fraction and $7.18 \%$ for $30 \%$ volume fraction. From distilled water, $8.56 \%$ of weight increased in $20 \%$ and $9.82 \%$ of weight increased in $30 \%$ volume fraction. For $48 \mathrm{hrs}$ normal water, the weight percentage is increased, we get $17.72 \%$ for $20 \%$ volume fraction and $15.76 \%$ for $30 \%$ volume fraction. From distilled water, $18.35 \%$ of weight increased in $20 \%$ and $9.94 \%$ of weight increased in $30 \%$ volume fraction.

- Shibata S. Cao Y. et al. [16] studied the mechanical properties of bagasse fiber-reinforced composites before and after alkali treatments. Were alkali-treated 
composites showed better mechanical properties than untreated fibers. Fibers treated with a $1 \% \mathrm{NaOH}$ solution showed good improvement. Approximately $30 \%$ in impact strength, increased $15 \%$ in bending and $13 \%$ increase in tensile strength. SEM observations showed an increase in fiber-matrix adhesion in chemically treated fibers. Figure 2 i.e (A) and (B) It was observed that the filaments in the untreated fiber packed together, but split after the alkali treatment.

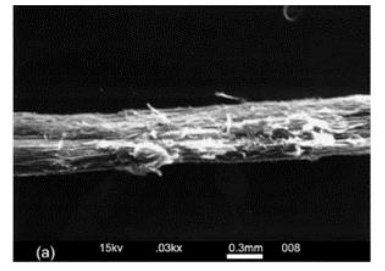

Figure 2 (A) Untreated Fiber

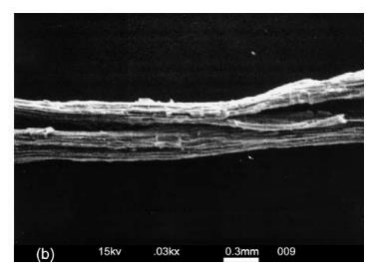

(B) Treated Fiber

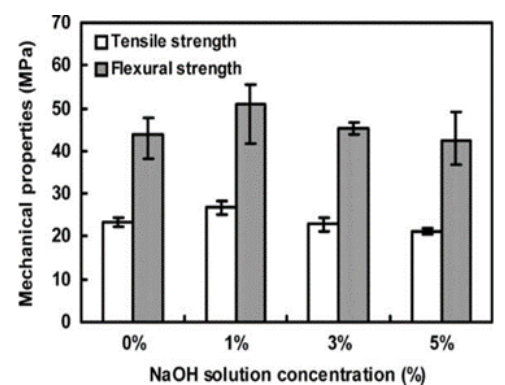

Figure 3 Alkali Treatment effect on properties of composites

- Figure 3 [17] shows that the mechanical properties (such as tensile strength and flexural strength) are optimized at different fiber loadings (using $\mathrm{NaOH}$ solution concentration as wt.\%). The $1 \% \mathrm{NaOH}$ treated fiber composites increases the tensile and flexural strength. As the $\mathrm{NaOH}$ concentration further increases to $3 \%$, the flexural strength increases slightly, while the tensile strength decreases. For the $5 \% \mathrm{NaOH}$ treated fiber composites, both tensile and flexural strength decreased and then compared with the untreated fiber composites.

- $\quad$ M.M. Kabir, H. Wang et al. [18] studied the hemp fibers were treated with alkali, acetyl, and silane chemicals. fibrous components such as cellulose, hemicellulose, and lignin constituents were separated from the treated fibers. Were chemical treatment changes the fiber structure by reacting to its components. Alkalization and acetylation reduce hemicellulose and lignin content in the fiber and Silane treatment could not remove the hemicellulose and lignin. Rather this treatment forms coverings on the surfaces of the fibers and fills the spaces between the microfibrils. Were treated fibers exhibit higher thermal stability compared with the untreated fibers.

\begin{tabular}{|c|c|c|c|c|}
\hline $\begin{array}{c}\text { Type of } \\
\text { fiber }\end{array}$ & $\begin{array}{c}-\mathrm{OH} \\
\text { stretching } \\
\text { (cellulose) }\end{array}$ & $\begin{array}{c}\mathrm{C}=\mathrm{O} \\
\text { stretching } \\
\text { (hemicellul } \\
\text { oses) }\end{array}$ & $\begin{array}{c}\mathrm{C}=\mathrm{O} \\
\text { stretching } \\
\text { (hemicellu } \\
\text { loses) }\end{array}$ & $\begin{array}{c}\mathrm{C}=\mathrm{O} \\
\text { stretching } \\
\text { (lignin) }\end{array}$ \\
\hline $\begin{array}{c}\text { Untreated } \\
\text { Treated }\end{array}$ & 3407 & 1737 & 1643 & 1249 \\
\hline Alkali & 3434 & - & 1650 & 1256 \\
\hline Silane & 3386 & 1737 & 1652 & 1251 \\
\hline $\begin{array}{c}\text { Acetylati- } \\
\text { on }\end{array}$ & 3419 & 1726 & 1643 & 1253 \\
\hline
\end{tabular}

Table-5 Infrared transmittance peaks (cm-1) of untreated and treated fibers

- In table 5 it can be understood from the spectra that some chemical reactions occurred during the different treatments. The broad range at $3407 \mathrm{~cm}-1$ is the characteristic band for $-\mathrm{O}-\mathrm{H}$ stretching for untreated fibers. Chemical treatments such as alkali, silane and acetylation shifted the band to $3434 \mathrm{~cm}-1$, $3386 \mathrm{~cm}-1$ and $3419 \mathrm{~cm}-1$, respectively and increased this intensity [19]. They indicate the reduction of hydrogen bonding in cellulosic hydroxyl groups, thereby increasing - $\mathrm{OH}$ concentration. As a result, the fibers hydrophilic nature decreased and more reactive $-\mathrm{OH}$ groups were exposed to the matrix. The band $1737 \mathrm{~cm}-1$ corresponds to the $\mathrm{C}=\mathrm{O}$ stretching in the acetyl groups of hemicelluloses of the untreated fibers. This band disappears for the alkali treated sample. This indicates that hemicelluloses were removed from the fiber surface. For the acetylated fiber, this band is shifted to 1726 $\mathrm{cm}-1$ and it indicates that partial of hemicelluloses was removed. This band is unchanged for the silane treated fiber. The increment of band for alkali (1650 $\mathrm{cm}-1)$ and silane $(1652 \mathrm{~cm}-1)$ treated fibers gave further indication that hemicelluloses were removed effectively by going through these treatments. The band at $1249 \mathrm{~cm}-1$ for untreated fiber is corresponded to the $\mathrm{C}=\mathrm{O}$ stretching in the aromatic ring of lignin. For alkali, silane and acetylation treated fibers this band was up-shifted to $1256 \mathrm{~cm}-1,1251.6 \mathrm{~cm}-1$ and $1253 \mathrm{~cm}-1$ respectively [20]. From these results, FTIR analysis shows that alkaline treatments and acetyl treatment remove the hemicellulose and lignin components from the fiber surface. In contrast, the silane treatment does not react with these components.

- In Table 6 observed that, in all cases the degradation temperatures of lignin, hemicelluloses and cellulosic constituents for acetylated fibers are higher than that of the untreated and alkalized pre-treated fibers. The table presents TGA analysis of the silane and silane 
over alkali treated fiber samples. The treated fibers show similar characteristics as the alkali treated fibers and best result was observed for $8 \%$ alkali pretreated silane treated fiber sample.

Table 6 Thermogravimetric analysis on hemp fiber with different chemical treatment.

\begin{tabular}{|c|c|c|c|c|c|c|c|}
\hline \multirow{3}{*}{\multicolumn{2}{|c|}{$\begin{array}{c}\text { Fiber } \\
\text { treatment }\end{array}$}} & $\begin{array}{c}\text { 2nd } \\
\text { stage } \\
\text { (hemicel } \\
\text { luloses } \\
\text { and } \\
\text { lignin) }\end{array}$ & $\begin{array}{c}\text { 3rd stage } \\
\text { (cellulosic } \\
\text { componen } \\
\text { ts) }\end{array}$ & $\begin{array}{l}\text { 2nd stage } \\
\text { (hemicell } \\
\text { uloses } \\
\text { and } \\
\text { lignin) }\end{array}$ & $\begin{array}{c}\text { 3rd stage } \\
\text { (cellulosic } \\
\text { componen } \\
\text { ts) }\end{array}$ & $\begin{array}{c}\text { 2nd } \\
\text { stage } \\
\text { (hemic } \\
\text { ellulose } \\
\text { s and } \\
\text { lignin) }\end{array}$ & $\begin{array}{c}\text { 3rd stage } \\
\text { (cellulosi } \\
\mathrm{c} \\
\text { compone } \\
\mathrm{nts} \text { ) }\end{array}$ \\
\hline & & $\begin{array}{l}\text { Temp } \\
\text { range }\end{array}$ & $\begin{array}{l}\text { Temp } \\
\text { range }\end{array}$ & $\begin{array}{c}\text { Temp } \\
\text { range }\end{array}$ & $\begin{array}{l}\text { Temp } \\
\text { range }\end{array}$ & $\begin{array}{l}\text { Temp } \\
\text { range }\end{array}$ & $\begin{array}{l}\text { Temp } \\
\text { range }\end{array}$ \\
\hline & & $\begin{array}{c}200-300 \\
{ }^{\circ} \mathrm{C} .\end{array}$ & $\begin{array}{c}320-400 \\
{ }^{\circ} \mathrm{C} .\end{array}$ & $\begin{array}{c}200-300 \\
{ }^{\circ} \mathrm{C} .\end{array}$ & $\begin{array}{c}320-400 \\
{ }^{\circ} \mathrm{C} .\end{array}$ & $\begin{array}{c}200- \\
300^{\circ} \mathrm{C} .\end{array}$ & $\begin{array}{c}320-400 \\
{ }^{\circ} \mathrm{C} .\end{array}$ \\
\hline \multirow{5}{*}{$\begin{array}{c}\mathrm{NaO} \\
\mathrm{H} \\
\text { treate } \\
\mathrm{d}\end{array}$} & $0 \%$ & 270 & 331 & 288 & 354 & 269 & 347 \\
\hline & $4 \%$ & 289 & 354 & 295 & 356 & 286 & 354 \\
\hline & $6 \%$ & 287 & 353 & 290 & 354 & 275 & 351 \\
\hline & $8 \%$ & 290 & 350 & 292 & 355 & 268 & 345 \\
\hline & $10 \%$ & 288 & 357 & 291 & 357 & 273 & 351 \\
\hline
\end{tabular}
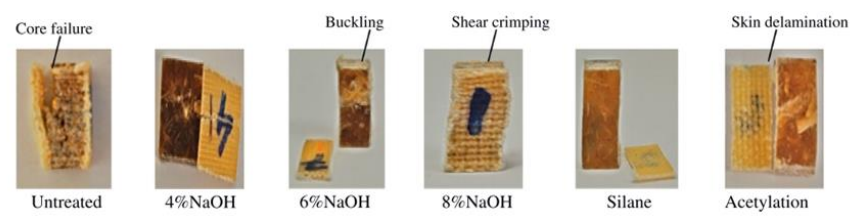

Figure 4 Compression failure modes of untreated and treated fiber composite

Figure 4 Shows that the treated samples have core shear crimping and skin wrinkling, which were not observed in untreated sample. Shear crimping of the core indicates a good bonding between the fiber and matrix [21]. The debonding indicates low stress transfer of com- pressive strength between the skin and core. However, high con- centration of alkali treated samples did not show debonding failure of the skin. As a result, all the treated samples showed better compressive strength as compared with the untreated composites. These results further prove the effectiveness of removing hemi- celluloses, lignin and cellulosic constituents of the fibers after alkali treatment can facilitate their bonding with the matrix.
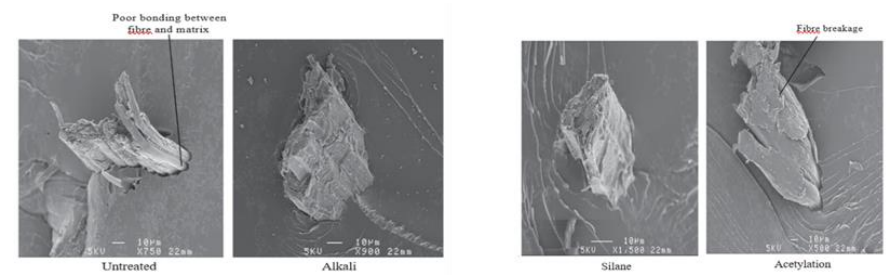

Figure 5 SEM micrograph different fracture surface of the composites.

In figure 5 fracture surfaces of bending test samples were examined by scanning electron microscope (SEM) to evaluate the degree of adhesion between the fiber and matrix. They examined different portion of the fractured surface from each specimen. In untreated fiber composite suffered with poor bonding between fiber and matrix. In alkali treated fiber composite, the fiber pull-out holes were less. The gap between fiber and resin was also unnoticeable. It indicates that, alkali treatment improved fiber matrix adhesion of the composites. On the other hand, silane treated composites large amount of resin adhered with the fiber's surface was observed. This indicates good adhesion between the fiber and the matrix. Similar observations were also visible from the acetylated composites [22]. SEM observations can be untreated samples compared with the chemically treated fiber composites samples showed improved fiber matrix adhesion properties.

\section{REVIEW OBJECTIVES}

This review focuses on the natural fiber (i.e hemp - bagasse) in composite development of low cost, enhances fuel efficiency with lightweight material good mechanical performance and biodegradable properties; an attempt was made to utilizing renewable resources for the development of natural fiber composite material for automotive application. Bio composites have attracted the attention of automakers for the design of lightweight parts. A significant amount of research has been done into different processing and manufacturing techniques to enhance these under different loading types. Bio composites have found a vast number of applications in automotive industry. Door panels, seatbacks, dashboards and package trays, head restraints and seatback linings are just some of the examples.

The present work has been undertaken to develop a composite material using hemp - bagasse fiber as reinforcement and to study its properties and the effect of different surface treatment on fibers. The more focus is on using bagasse fiber as filler in composite material, which is a waste from sugarcane mills and its worldwide production too high. It is a challenge to create better material to improve mechanical properties and reduce water absorption property and cost. Some automotive industry uses the only hemp to make door panels. However, we can add some amount of bagasse fiber add to it and check the properties. It aims to reduce weight over a traditional vehicle, reduce fuel consumption and $\mathrm{CO} 2$ emission, and reduce the price. 


\section{International Journal of Engineering Applied Sciences and Technology, 2021 \\ Vol. 6, Issue 1, ISSN No. 2455-2143, Pages 376-382 \\ Published Online May 2021 in IJEAST (http://www.ijeast.com)}

\section{CONCLUSION}

The present review was undertaken, with an objective to developed the field of hemp-bagasse fiber polymer composites and to study the various properties of the composites. This review reports on the chemical processes used for fibers' surface treatment to remove the moisture content. Natural fiber-reinforced polymer composites are generally lower in strength than hybrid composites. The literature review shows that the overall mechanical properties of natural fiber reinforced hybrid composites depended entirely on the amount and type of fiber used. Flax, glass, and hemp are utilized in the interior door panels. Based on the review Bagasse fiber increased flexural strength while hemp fibers increased the composite toughness, bagasse fiber to make bio-composite material also helps in making new revolution to sustain our natural resources. The development of composite materials based on reinforcement of hemp-bagasse fibers in a single matrix, which will lead to the development of hybrid composites with a great diversity of material properties, it can be a way to increase the mechanical properties.

\section{REFERENCES:}

1. O. D. Samuel, S. Agbo, and T. A. Adekanye, "Assessing Mechanical Properties of Natural Fibre Reinforced Composites for Engineering Applications," J. Miner. Mater. Charact. Eng., vol. 11, no. 08, pp. 780-784, 2012, doi: 10.4236/jmmce.2012.118066.

2. N. M. Mathur and K. Bairwa, "A literature review on Composite material and scope of Sugar cane Bagasse," vol. 5, no. 4, pp. 125-133, 2017.

3. D. Trivedi, "Composite And Chemical Treatment Done To A Review On Bagasse Fiber Reinforced Polymer Composite And Chemical Treatment Done To Improve Its Properties .," no. April 2015, 2016.

4. L. Mohammed, M. N. M. Ansari, G. Pua, M. Jawaid, and M. S. Islam, "A Review on Natural Fiber Reinforced Polymer Composite and Its Applications," Int. J. Polym. Sci., vol. 2015, 2015, doi: 10.1155/2015/243947.

5. N. F. Composites, A. N. O. View, A. Kumar, and R. Prasad, "CHAPTER 2," pp. 10-29, 2014.

6. A. Thygesen, Properties of hemp fibre polymer composites, vol. 11, no. April. 2006.

7. D. Verma, P. C. Gope, M. K. Maheshwari, and R. K. Sharma, "Bagasse fiber composites-A review," J. Mater. Environ. Sci., vol. 3, no. 6, pp. 1079-1092, 2012.
8. S. Akarsh, H. R. Darshan, K. M. Chandrashekar, and P. C. R, "a Study on Mechanical Properties of HempBagasse Fibers Reinforced With Epoxy Hybrid Composite,” Int. Res. J. Eng. Technol., vol. 4, no. 6, pp. 2108-2111, 2017.

9. E. City, "Water Absorption Effect on Hemp Bagasse Fiber Reinforced With Epoxy Hybrid Composite," Int. Res. J. Eng. Technol., vol. 4, no. 6, pp. 30803084, 2017.

10. A. Al-Maharma and N. Al-Huniti, "Critical Review of the Parameters Affecting the Effectiveness of Moisture Absorption Treatments Used for Natural Composites," J. Compos. Sci., vol. 3, no. 1, p. 27, 2019, doi: 10.3390/jcs3010027.

11. X. Li, L. G. Tabil, and S. Panigrahi, "Chemical treatments of natural fiber for use in natural fiberreinforced composites: A review," J. Polym. Environ., vol. 15, no. 1, pp. 25-33, 2007, doi: 10.1007/s10924-006-0042-3.

12. M. Engineering, "Fabrication and Testing of Hemp Fibre," no. May, pp. 1-8, 2016.

13. R. Bhoopathi, M. Ramesh, and C. Deepa, "Fabrication and property evaluation of bananahemp-glass fiber reinforced composites," Procedia Eng., vol. 97, pp. 2032-2041, 2014, doi: 10.1016/j.proeng.2014.12.446.

14. N. S. Venkatesha Gupta, Akash, K. V. Sreenivasa Rao, and D. S. Arun Kumar, "Fabrication and evaluation of mechanical properties of alkaline treated sisal/hemp fiber reinforced hybrid composite," IOP Conf. Ser. Mater. Sci. Eng., vol. 149, no. 1, 2016, doi: 10.1088/1757899X/149/1/012093.

15. M. Tewari, V. K. Singh, P. C. Gope, and A. K. Chaudhary, "Evaluation of mechanical properties of bagasse-glass fiber reinforced composite," J. Mater. Environ. Sci., vol. 3, no. 1, pp. 171-184, 2012.

16. Y. Cao, S. Shibata, and I. Fukumoto, "Mechanical properties of biodegradable composites reinforced with bagasse fibre before and after alkali treatments," Compos. Part A Appl. Sci. Manuf., vol. 37, no. 3, pp. 423-429, 2006, doi: 10.1016/j.compositesa.2005.05.045.

17. J. Rout, M. Misra, S. S. Tripathy, S. K. Nayak, and A. K. Mohanty, "The influence of fibre treatment of the performance of coir-polyester composites," Compos. Sci. Technol., vol. 61, no. 9, pp. 13031310, 2001, doi: 10.1016/S0266-3538(01)00021-5. 
18. M. M. Kabir, H. Wang, K. T. Lau, F. Cardona, and T. Aravinthan, "Mechanical properties of chemicallytreated hemp fibre reinforced sandwich composites," Compos. Part B Eng., vol. 43, no. 2, pp. 159-169, 2012, doi: 10.1016/j.compositesb.2011.06.003.

19. M. S. Sreekala, M. G. Kumaran, and S. Thomas, "Oil palm fibers: Morphology, chemical composition, surface modification, and mechanical properties," J. Appl. Polym. Sci., vol. 66, no. 5, pp. 821-835, 1997, doi: $10.1002 /($ sici) $1097-$ 4628(19971031)66:5<821::aid-app2>3.0.co;2-x.

20. S. Ouajai and R. A. Shanks, "Composition, structure and thermal degradation of hemp cellulose after chemical treatments," Polym. Degrad. Stab., vol. 89, no. 2, pp. 327-335, 2005, doi: 10.1016/j.polymdegradstab.2005.01.016.

21. N. Gupta and E. Woldesenbet, "Characterization of flexural properties of syntactic foam core sandwich composites and effect of density variation," J. Compos. Mater., vol. 39, no. 24, pp. 2197-2212, 2005, doi: 10.1177/0021998305052037.

22. M. Pracella, M. M. U. Haque, and V. Alvarez, "Functionalization, compatibilization and properties of polyolefin composites with natural fibers," Polymers (Basel)., vol. 2, no. 4, pp. 554-574, 2010, doi: 10.3390/polym2040554. 